\title{
A model for forming tolerance in profession-oriented text translators as part of the process of developing their sociocultural competence
}

\author{
Irina Telezhko - Yulia Biryukova - Victoria Kurilenko
}

DOI: 10.18355/XL.2019.12.01.09

\begin{abstract}
The research focuses on forming tolerance in profession-oriented text translators as part of the process of developing their sociocultural competence. To this end, the author analyzes the notion of "tolerance" in Russian, German and English linguistic culture and the specifics of profession-oriented text translators' work. Based on a survey of professional translators, the concept of "profession-oriented text translators' tolerance" is considered a personal professional quality (in this case, related to geologists). The author justifies its importance and proposes a model for forming translators' tolerance at four stages of developing the sociocultural competence of profession-oriented text translators. This professionally important quality will help translators successfully carry out cross-cultural communication in their professional sphere.
\end{abstract}

Key words: tolerance, profession-oriented translation, cross-cultural communication, professional sphere, sociocultural competence

\section{Introduction}

Translation, being one of the types of mediation, is recognized as special and perfect among them (Latyshev, Semenov,2003). The concepts of "linguistic mediation" and "linguistic mediator" are used when addressing the process of communication of multilingual communicants with the help of a mediator. The role of a translator is defined as a "cross-cultural mediator", a third-dimensional synergetic person, who is a visible third party working across cultures and incorporating his or her mentality, cultural identity, cultural background to perceive, interpret, construct and translate the metatextual sense of messages of a foreignlanguage culture (Gurov, Vulfov, Galyapina, 2004 :14).

The essence of translational mediation in the professional sphere is an accurate transfer of scientific and technical information in accordance with the social and cultural norms and traditions adopted within the social institute of science and technology in Russia as well as sociocultural patterns of professional communication. Profession-oriented text translators work in their specific professional sphere and most often deal with texts traditionally related to the scientific prose style. Each text, including profession-oriented ones, is culturally conditioned. The difficulties of a sociocultural nature in understanding and translating profession-oriented texts include the following facts that cause communicative failures:

- In communication, the sender and the recipient in the professional sphere construct their statements in accordance with cultural traditions, norms and style corresponding to this communication sphere;

- Specialists in various professional fields, including scientific and technical areas, representing different cultures, treat the same scientific and technical problems in different ways as far as different cultural approaches are used in their education that cause differences in basic subject knowledge;

- Differences in laws, rules, requirements, restrictions, and norms that function within the social institute of science and technology; 
- Differences in values and perceptions;

- Concepts (stereotypes and styles of thinking, differences in views of life,

etc.);

- Structural and semantic features of linguistic units (language images, phraseology, speech behavior, code system).

The above sociocultural features have a significant impact on how translators understand foreign-language texts and create target translations; therefore, translators should not simply understand the meaning of sociocultural information contained in the source text but compare it with the existing concepts in the target language, selecting information that is missing in the target text recipient's cognitive background. This means that a translator, recognizing and accepting differences existing between representatives of various cultures, and understanding and respecting different ways of life, should show tolerance to representatives of other cultures.

Thus, it seems obvious that it is necessary to build relationships based on a tolerant perception of the "other". According to V.M. Zolotukhin, tolerance in the sociocultural context contributes to the removal of sociocultural tension (Zolotukhin, 2005:13). S.K. Bondyreva emphasizes the mutual influence of tolerance and communication, their mutual dependence: on the one hand, only tolerant communication can be productive, on the other hand, tolerance is formed only through communication of individuals with their like (Bondyreva 2003). Therefore, the need to form tolerance in profession-oriented text translators is dictated by the content and nature of their activities.

\section{Tolerance of profession-oriented text translators}

In order to define the concept of tolerance related to profession-oriented text translators, we shall consider various approaches to the definition of this concept.

At present, tolerance is studied from the standpoint of philosophy, sociology, linguistics, ethnography, psychology, and pedagogics, i.e., on an interdisciplinary basis.

The content of this concept being analyzed in Russian science includes the following generally recognized criteria:

$>$ From the standpoint of the semantic approach, tolerance is defined as "patience", "forbearance", "large-mindedness", i.e., "attitude";

$>$ From the standpoint of an approach based on humane-value interaction of people, tolerance is manifested in the desire to achieve mutual understanding and harmonization of motives, attitudes and orientations;

$>$ Tolerance is considered as a sociocultural value and a norm that began to be put forward at the center of ideas about ideological values and social norms of the emerging humanistic civilization, in which the "culture of tolerance" is the most important component of the general social environment;

$>$ From the standpoint of psychology, tolerance is a personal quality characterized by the ability to achieve mutual understanding, the recognition of spiritual values of one's own personality and the manifestation of a value attitude to other people and their views, the ability to change, when required, one's own viewpoint, attitude or mind, and the ability to cooperate (Bondyreva 2003, Vulfov, 2002, Prokhorov, 2003, Telezhko, 2016,). 
When comparing the views of representatives of English and German science, one can see specific features in their interpretation of the notion of tolerance. In English cultural tradition, tolerance is the willingness to be tolerant, condescending, allowing the existence of different opinions without discrimination; indulgence, the ability to perceive without demur a person or a thing. In German linguistic culture, Toleranz means tolerance, readiness to mutually recognize rules (Forst, 2002, Hoffmann, 2014, Nielsen, 1990,Geyer 2014).

In spite of the fact that researchers differently characterize the concept of tolerance, in all the above definitions we can identify one common feature, i.e., the ability to achieve mutual understanding on the basis of respect and acknowledgment.

However, do translators always show tolerance when they translate profession-oriented texts?

To determine the level of tolerance, professional translators were interviewed on the translators" site "City of translators" [http://www.trworkshop.net/] based on questionnaire including 5 questions:

1. Tolerance is: a) respectful attitude; b) indulgence; c) mutual understanding between representatives of different cultures?

2. I am always tolerant of presented scientific and technical information contained in foreign texts.

3. What difficulties do I have in translating profession-oriented texts?

4. I am able to place myself in another person's position, to cope with the problem situation when translating profession-oriented texts.

5. What knowledge, skills or competencies do I lack to effectively carry out the interaction between specialists of other linguistic cultures in the professional sphere?

\section{Table 1: questionnaire's questions}

The results of the survey showed that in some cases, some translators do not show tolerance, in particular, at the stage of understanding and interpreting texts. The reasons for this are:

- Insufficient knowledge of the sociocultural features of communication among specialists of foreign-language cultures;

- Differences in moral values between the translator and the author of the source text;

- Non-acceptance of one or another position on a certain scientific problem because profession-oriented text translators, as a rule, are experts in a certain knowledge area. Here is an example from a translator's professional practice: "Recently I came across an error in the instructions for an electrical circuit: well, if you installed a bridge where they wrote, there would be a big bang. In what concerns technical translations, it is often the translator who is the last barrier to stupidity. And here you have to stand fast." Thus, tolerance of profession-oriented text translators is also characterized by the availability of subject knowledge in their main specialty.

As researchers note, tolerance, in the cognitive "dimension", is most clearly manifested in situations of contradiction, divergence or conflict of views, etc. [Bondyreva, 2003]. Gradual and tolerant introduction to other national and cultural values and knowledge allows translators to correctly interpret sociocultural 
information in the source text, compare it with the sociocultural characteristics of their own native culture and adequately transfer them to the target language. Tolerance helps translators successfully perform their activities and characterizes them socially and psychologically.

For the foregoing reasons, tolerance of profession-oriented text translators can be defined as a personal professional quality characterized by their knowledge of the subject area and ability to achieve mutual understanding between representatives of different cultures in the professional communication sphere based on recognition of the diversity of cultures, values, norms in the professional sphere that manifests itself in certain communicative situations.

\section{Components of the model for forming tolerance in profession-oriented text translators}

To determine the components of the proposed model for forming tolerance in profession-oriented text translators, we shall consider various approaches to the structure of tolerance.

Analyzing the structure of tolerance, researchers distinguish various components. Thus, B.Z. Vulfov views tolerance as a set of communicative skills that ensure a person's preparedness for coexistence with other people, communities, circumstances, the ability to understand and accept them as they are (Vulfov, 2002: 13). In the study of the structure of tolerance as a socially significant value, I.V. Krutova distinguishes the following components: cognitive, emotional-axiological, personal-semantic, and activity-oriented. The cognitive component means fixing in the minds of students the result of acquiring knowledge about tolerance. The emotional-evaluative component is associated with the peculiarities of emotional perception of knowledge about tolerance. The personal-semantic component is the recognition and acceptance of the personal sense of the socially significant "tolerance" value. The activity-oriented component implies the subject's regulation of his (or her) own actions [Krutova, 2003:28-29]. M.A. Perepelitsyna distinguishes a cognitive, a behavioral and perceptive-affective components. The cognitive component performs informational and semantic functions and records the result of acquiring knowledge of tolerance in the human mind. The perceptive-affective component is associated with a function of understanding and an emotional function (using the language to express a personal (subjective) attitude to the message content or to the interlocutor). The behavioral component performs a regulative function. The basis of this component is the subject's action based on tolerance [Perepelitsina, 2004: 26-35].

Relying on the above approaches and the specifics of profession-oriented text translators' work, we shall define the components of a model for forming tolerance.

The translator's ability to act as a mediator in the process of communication between representatives of professional communities from different countries depends largely on the knowledge of a foreign specialized culture (conditioned by the social division of labor and the social institution) and the ability to correlate it with the sociocultural peculiarities of professional communication in Russia. Taking into account the fact that tolerance is formed based on knowledge of the culture, norms, values, and rules of the target-language country, the cognitive component of profession-oriented text translators' tolerance will include:

- Sociocultural knowledge;

- Knowledge of the specialized culture, values of both the target-language country and Russian specialists;

XLinguae, Volume 12 Issue 1, January 2019, ISSN 1337-8384, eISSN 2453-711X 
- Students' knowledge about "tolerance" as a social value and possible situations of its manifestation in the professional communication sphere;

- Integrative knowledge of the main specialty.

This component suggests that future translators should realize the diversity of the world, mentalities and ways of mutual understanding among representatives of different cultures.

The behavioral component involves the ability to regulate one's own speech behavior depending on the communicative situation based on tolerance.

- Knowledge of the norms within the social institute of science and technology of the target-language country;

- Ability to tolerate a statement (i.e., perceiving opinions and judgments of other people as an expression of their views that have every right to exist, no matter how much they may differ from one's own views).

The emotional-axiological component suggests that tolerance should be manifested in feelings or beliefs and promoted as an evaluation criterion in perceiving, recognizing and understanding representatives of foreign-language communities. This component includes knowledge of the specifics of communication among specialists in the professional sphere.

The identified knowledge and skills will contribute to the formation of tolerance among the intended translators, their readiness for communication in the professional sphere as "mediators between cultures". It seems to be expedient to integrate the formation of tolerance as a professional quality among students into the process of developing the sociocultural competence of profession-oriented text translators.

\section{Principles of forming tolerance in profession-oriented text translators}

The proposed model for forming tolerance in profession-oriented text translators is based on the following methodological principles: (1) the contrastivecomparative principle of co-studying cultures and civilizations; (2) the principle of implementing a student-centered approach; (3) the principle of profession-oriented education (considering future specialties and professional interests of students); and (4) the principle of variability, which implies, within the educational material structure, variability of its content, depending on the language and specialization of the target text. These principles are reflected in the process of forming translators' tolerance.

\section{What methods of organizing and implementing educational and cognitive activities are used for forming tolerance in profession-oriented text translators?}

It is proposed to form tolerance in professionally oriented text translators as a professionally important quality based on the integrative model for developing the sociocultural competence proposed by I.V. Telezhko (Telezhko, 2016). The researcher proposes to introduce a special course ("Specialized culture") at the profession-oriented stage of training so as to familiarize students with the specifics of professional communication among specialists of another linguistic community and the need for its comparative analysis with professional communication among specialists in the scientific and technical sphere both in Russia and in the targetlanguage country. The following concepts are supposed to be explained to the students: "communication sphere", "sociocultural information", "sociocultural realities", "specialized culture", "linguistic world-image", "concept", "genre", which will make it possible to form the cognitive component of profession-oriented text translators' tolerance. At the analytical stage, in teaching the students to 
perceive and understand sociocultural information in the source text, a problemsearch teaching method and a system of analytical exercises are used so that they could learn to analyze the socio-cultural peculiarities of special discourse. At the same time, the teacher draws the students' attention to the value priorities of other cultures, a different logical and semantic structure of special discourse genres and speech behavior of specialists in the professional communication sphere. It should be noted that, in understanding the source text, translators will rely on subject knowledge of their main specialty. It is important that the students consciously perceive the differences between the specialized cultures of the sender and the recipient and also search for contact points between the two cultures, which will allow the emotional-axiological component of translators' tolerance to be formed. At the synthetical stage of training, the students learn to select equivalents in their native culture to linguistic representations of concepts using the case method. The teacher proposes a communicative situation to the students, e.g., "You are doing practical training at a translation company. You have to translate a text where the "Ordnung" concept is frequently mentioned. When handling the task, you have encountered some difficulties in translating the linguistic representations of this concept into Russian. How is this problem to be solved?" The teacher suggests investigating the "Ordnung" concept in comparison with the "Order" concept to reveal their conceptual features. The students are asked to pick up equivalents to the German concept "Ordnung". For many Russian students, the word "Ordnung" is associated only with "order" or "discipline". Performing a number of tasks based on authentic German geological texts, the students will come to the conclusion that this concept will have different meanings in German geological discourse, namely: unit, hierarchy, ranging area, structure, etc. The case-method is aimed at acquiring knowledge of the specifics of communication among specialists in the professional sphere and developing the ability to tolerate statements in order to form the behavioral component of translators' tolerance.

\section{Results}

In order to prove the reliability and efficiency of the created model, an experimental training course was organized at the Peoples' Friendship University of Russia, in which 30 students majoring in geology were randomly tested to estimate their tolerance level.

The tasks of the educational experiment were defined as follows:

- Developing value perception of facts of the specialized culture to promote effective cross-cultural communication;

- Forming tolerant consciousness in students to prepare them for the role of "mediators between cultures";

- Developing the sociocultural competence of profession-oriented text translators to promote interaction between representatives of various linguistic communities in the professional sphere.

Tolerance of intended profession-oriented text translators was formed on the basis of German geological texts containing sociocultural information.

As part of the experiment, the students attended a course of lectures on the "specialized culture" intended to familiarize them with the specifics of professional communication (in our case, related to German geologists) and the need for its comparative analysis with professional communication of Russian geologists. The teacher pointed out the difference in the representation of subject knowledge in German geological discourse and explained the importance of sociocultural knowledge for understanding foreign-language texts.

At the analytical stage of developing the ability to identify and analyze representations of German geological concepts in the source text for their subsequent

XLinguae, Volume 12 Issue 1, January 2019, ISSN 1337-8384, eISSN 2453-711X 
translation into Russian, it is appropriate to use problem-search tasks involving information technologies. The teacher introduced the "Erde" concept to the students and explained that this concept has various linguistic representations, i.e., in order to identify it, its nominative field should be known. So that the students could familiarize themselves with the notions of "nominative field", "concept core" and "periphery", they were asked to consider the "Erde" concept. Using the acquired knowledge, the students analyzed the "Erde" concept all by themselves. For this purpose, they received an instruction indicating the computer information technologies which they can use to fulfill the tasks. After the students had become aware of the "Erde" concept nominative field, they were asked to isolate the "Erde" concept from several minitexts. For developing the conceptual sphere, the students were given a task "to construct the nominative field of this concept taking into account the professional sphere of geologists and compare it with that of the "Erde" concept. The students came to a consensus that the nominative field of the Earth concept in Russian geological discourse is represented wider than that of the Erde concept in German geological discourse.

At the synthetical stage of training, tolerance was formed by means of the case method in developing the ability to select equivalents in the native culture to the linguistic representations of German geological discourse based on several mini-texts containing the "Ordnung" concept.

In the course of monitoring the level of tolerance formation among the students, the findings of the ascertaining and final sections were compared based on the questionnaire (Fig. 1), and a positive change was revealed in the level of tolerance of profession-oriented text translators. The dynamics of changes in results are shown in

Fig. 2.

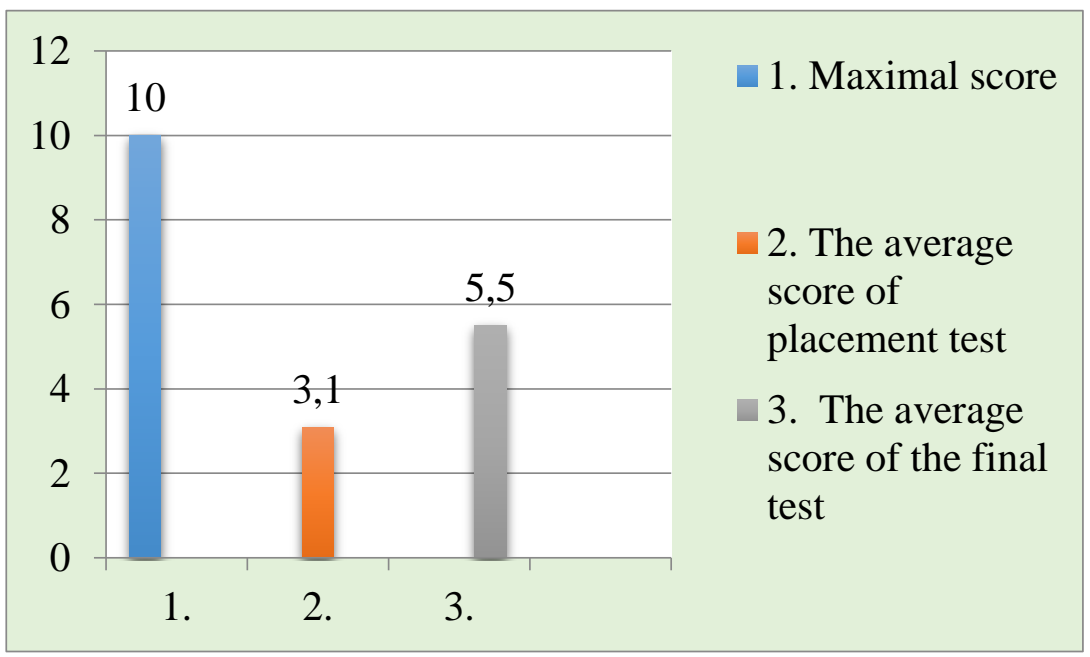

Figure 1: The dynamics of changes in results

The results of the training conducted as part of the profession-oriented, analytical and synthetical stages show as follows:

- The tolerance level of intended profession-oriented text translators has significantly increased; 
- The students have formed their tolerant consciousness;

- The students have developed the value perception of facts of the specialized culture;

- The students have acquired the ability to place themselves in another person's position, to cope with problem situations when translating profession-oriented texts;

- The students have acquired the sociocultural competence. While working on the case, the students learned to correlate "images" of the foreign culture with those of their native culture in translating geological discourse.

Thus, the proposed model for forming tolerance in profession-oriented text translators will be intended not only to develop professionally important qualities of translators as "mediators between cultures" but also to form the sociocultural competence that will improve the quality of profession-oriented translations and contribute to successful cross-cultural communication.

\section{Bibliographic references}

BONDYREVA, S.K. 2003. Tolerance (introduction to the problem) [Text]. S.K. Bondyreva, D.V. Kolesov. Moscow: MPSI Publ., 240 p.

VULFOV, B.Z. 2002. Tolerance education: Essence and means. Vneshkolnik, no. 6. ZOLOTUKHIN, V.M. 2005. Tolerance as a problem of philosophical anthropology: Doc. Sci. (Pedagogical Sciences) Thesis. Kemerovo, 341 p.

LATYSHEV, L.K. - SEMENOV, A.L. 2003. Translation: Theory, practice and teaching methods. Moscow: Akademia Publ. 192 p.

KRUTOVA, I.V. 2003. Forming high school students' attitude towards tolerance as a socially significant value in teaching the humanities: Cand. Sci. (Pedagogical Sciences) Thesis. Volgograd, $231 \mathrm{p}$.

PEREPELITSINA, M.A. 2004. Forming pedagogical tolerance in future teachers: Cand. Sci. (Pedagogical Sciences) Thesis. Volgograd, $176 \mathrm{p}$.

PROKHOROV, YE.P. 2003. Tolerance as the value and normative core of the information order in a democratic society. Vestnik Moskovskogo Universiteta. Series: 10, Zhurnalistika, no. 5, pp. 69-97.

TELEZHKO, I.V. 2016. Integrative model for developing sociocultural competence of profession-oriented text translators (German language, vocational education level): Cand. Sci. (Pedagogical Sciences) Thesis. Moscow, 255 p.

GUROV, V.N. - VULFOV, B.Z. - GALYAPINA, V.N. 2004. Formation of a tolerant personality in a multiethnic educational environment [Text]. Moscow: Pedagogical society of Russia, $240 \mathrm{p}$.

FORST,R. 2000. Toleranz. Gerechtigkeit und Vernunft. Frankfurt/Main, pp. 144161.

HOFFMANN, H. 2014.Codes der Toleranz. Herder, Freiburg im Breisgau,

NIELSEN, F. W. 1990. Drei Briefe. Freiburg: Toleranz, Cop., 24 p.

GEYER, R. 2014. Minderheiten und Toleranz. Themenblätter im Unterricht/Nr.105 Bonn, Available online: https://www.google.ru/url?sa=t\&rct=j\&q=\&esrc=s\&source=web\&cd=1\&ved=0ahU KEwjruc_b3enXAhViCZoKHas5BP0QFggoMAA\&url=http\%3A\%2F\%2Fwww.bp b.de\%2Fsystem\%2Ffiles\%2Fdokument_pdf\%2F5003_tb105_Minderheiten_Toleran zen_online.pdf\&usg=AOvVaw0npS6CbEtbuO9XBRkVQM2O 
Words: 3624

Characters: 26657 (14,81 standard pages)

Senior lecturer Irina Telezhko, $\mathrm{PhD}$

Department of Foreign Languages,

Engineering Faculty

Peoples' Friendship University of Russia (RUDN University)

Miklukho-Maklaya street, 6

117198 Moscow

Russia

irina-telezhko@mail.ru

Assoc. Prof., Yulia Biryukova, PhD

Russian language department

Medical Institute

Peoples' Friendship University of Russia (RUDN University)

Miklukho-Maklaya street, 6

117198 Moscow

Russia

yu.birukova@gmail.com

Prof., Victoria Kurilenko, $\mathrm{PhD}$

Head of Russian language department

Medical Institute

Peoples' Friendship University of Russia (RUDN University),,

Miklukho-Maklaya street, 6

117198 Moscow

Russia

vbkurilenko@gmail.com 